\title{
Neurodevelopment and Cognitive Impairment in Parents and Progeny of Perinatal Dietary Protein Deficiency Models
}

OPEN ACCESS

Edited by:

Kathleen C. Page,

Bucknell University, United States

Reviewed by:

Yinghua Yu,

Xuzhou Medical University, China

Nafisa M. Jadavji,

Midwestern University, United States

*Correspondence:

Nosarieme O. Abey

nosariemeomoregie@gmail.com

Specialty section:

This article was submitted to Neuroenergetics, Nutrition and Brain

Health,

a section of the journal

Frontiers in Neuroscience

Received: 14 May 2019

Accepted: 24 July 2019

Published: 21 August 2019

Citation:

Abey NO, Ebuehi OAT and

Imaga NOA (2019)

Neurodevelopment and Cognitive Impairment in Parents and Progeny

of Perinatal Dietary Protein Deficiency

Models. Front. Neurosci. 13:826.

doi: 10.3389/fnins.2019.00826

\section{Nosarieme O. Abey*, Osaretin A. T. Ebuehi and Ngozi O. A. Imaga}

Department of Biochemistry, Faculty of Basic Medical Sciences, College of Medicine, University of Lagos, Lagos, Nigeria

There is an absolute dependence of the concept of development on supply of adequately balanced nutrients especially during the perinatal age which is critical to development. Therefore, an upgraded nutrition is specially required during gestation and lactation, as this is the critical period of neurodevelopment. This study sought to investigate the effect of protein deficiency during gestation $\left(F_{0}\right)$ and lactation through to adolescence on neurological functions of subsequent $\left(F_{1}\right.$ and $\left.F_{2}\right)$ generations, establishing the possible consequential mechanistic association. Rats in four groups were fed different rations of protein diets (PD) as formulated: 21\% PD, 10\% PD, 5\% $\mathrm{PD}$ and control diet (standard rat chow, containing 16-18\% protein), from adolescent through to gestation and lactation, next generations were weaned to the maternal diet group. Neurobehavioral studies (which include; Surface righting reflex, Negative geotaxis, Learning and Memory tests), brain oxidative stress and quantification of serotonin and dopamine levels in the brain were conducted. Result shows significantly altered neurobehavior, reflected in the reduction of reflex response and postural reaction score at $P \leq 0.05$. There was also a transgenerational cognitive impairment of brain function in the F-generations, following perinatal protein malnutrition as shown in the Y-maze result, measuring spatial memory and Morris water maze result (cognition), providing a background for the observed sensorimotor response. The significant increase in dopamine level, decrease in the antioxidant capacity of the protein deficient brain groups are consistent with significantly altered serotonin system, critical to neurodevelopment and functional activities of learning and memory. Therefore, persistent early life protein deficiency mediates dysfunction in neurodevelopment and this involves life-long changes in key neurotransmitters and the brain redox status underlying the neurobehavioral display.

Keywords: neurobehavior, cognitive function, protein deficiency, neurotransmitter, transgeneration, perinatal

\section{INTRODUCTION}

Epidemiological studies have indicated that perinatal age exposures; including diet and nutrition affects directly later life developments, due to a shift or programed conditions. One of the well reported consequences are highly induced integrated responses in the endocrine homeostasis. which results in later life to subsequent and persistent changes in developmental trajectory yielding 
an altered phenotype which may appear as a physiological defect (Chan et al., 2011). Evidence of the dependence of brain development on nutrition is increasingly gaining interest. Nutritional status has been demonstrated to be associated with postnatal brain growth and maturation, subsequently impacting the neurodevelopment which may persist to adolescence (Black, 2018). Nutrition could also potentially protect against injury (Hurley et al., 2016). During the critical period of brain development ( $0-2$ years), i.e., the first 1,000 days, brain development is rapid, with nutrition playing an important role as one of the environmental influences on the coding and expression of the genetic code for structural and functional impact. Subsequent cognitive and emotional process coupled with the entire brain development in animal and human subjects have recently illustrated that the duration of exposure, chronicity, and severity of nutritional deficiencies have differential effects on brain development (Colombo et al., 2018). Fetal and neonatal programing have been reported to be the underlying mechanism for the far-reaching adverse consequences in humans following inadequate protein intake during gestation and postnatal periods (Wu, 2016). This risk factor results in not only impaired growth of fetuses and infants, but also some other problems such as metabolic syndrome (including hypertension, obesity, and diabetes) and low quality of life as adults (Sosa-Larios et al., 2017). There have been quite a few focuses on unveiling nutraceutical significance in neurodevelopment, which has contributed immensely to disability in individuals who bear the burden. In developing/lowresource settings it may be associated with a significant risk of impoverishing the health reserves which threatens survival and deepens poverty. This study sought to investigate the effect of maternal protein deficiency during gestation $\left(\mathrm{F}_{0}\right)$ and lactation on neurological functions of subsequent $\left(\mathrm{F}_{1}\right.$ and $\mathrm{F}_{2}$ ) generations, establishing the possible consequential mechanistic association.

\section{MATERIALS AND METHODS}

\section{Ethics Statement}

This study was carried out in accordance with the guidelines of health research Act 2004, for standard care and use of laboratory animal models. Ethical approval was given by the Health Research Ethics Committee (HREC) of College of Medicine University of Lagos (REC 11), Nigeria.

Forty virgin female Sprague Dawley rats (aged 6-8 weeks) were obtained from the animal house of the College of Medicine University of Lagos, Lagos Nigeria (Figure 1). Following the ethics of the standard care of animal models in research, rats were kept in groups in clean and capacious plastic cages (seven per cage) under standard laboratory conditions including well aerated room, good lighting, with suitable temperature $\left(30^{\circ} \pm 2^{\circ} \mathrm{C}\right)$ in a neat environment and at a 12-h light/dark cycle. The animals were divided into four (4) groups and acclimatized for 2 weeks, where they had access to standard rat chow and water ad libitum.

\section{Grouping}

The grouping was based on the diet received by the rat. Grouped rats received ad libitum formulated diets which include either of these diet formulations: 21\% PD (protein diet), 10\% PDD (Protein deficient diet 1), 5\% PDD (Protein deficient diet 2), and CP (standard rat chow, containing $16-18 \%$ protein) throughout gestation and lactation, forming Groups 12, 3 and 4, respectively, and pups were weaned to maternal diet.

\section{Diet Formulation}

The varying protein quality diet for rat was formulated using local materials such as: Maize, SBM, GNC, Fish meal cassava starch, oil etc., all in varying percentages toward the attainment of the desired percentage of protein in the diet. This feed was formulated by the help of some experts at federal institute of industrial research Oshodi (FIIRO). Formulated feeds were given to the rats.

\section{Prenatal Treatment}

Vaginal cytology was evaluated 3 weeks pre-breed period, and the rats were time-mated with a certified reproductive male in each treatment group, the confirmed pregnant rats were separated to produce $F_{1}$ generation, this process was repeated for $F_{1}$ generation to produce $F_{2}$ generation, while the different diet group feeding continues. Presence of spermatozoa in vagina smear confirms day 1 of pregnancy. Weaning was done at postnatal day $21-28$.

\section{Reflex and Sensorimotor Test Surface Righting Reflex (SRR)}

The test was evaluated on postnatal day 2 through to 6 . This test was carried out to measure the motor function and coordination by placing pups in a supine position and the time taken to adopt normal position was recorded, scored within cut-off time of $0-3 \mathrm{~s}$ (Naik et al., 2015).

\section{Negative Geotaxis Reflex}

The vestibular and proprioceptive functions were evaluated in rats (postnatal day $2-14$, every other day) were placed head down on an inclined board (about $45^{\circ}$ ), the time it took the animal to show a postural reaction by turning upright normally was recorded and scaled to score (Naik et al., 2015).

\section{Neurobehavioral Tests}

At six (6 weeks), offspring were randomly selected $(n=5)$ for different neurobehavioral trainings and trials.

\section{Y-Maze}

The test was conducted as a modified method described by Yarube et al. (2016), The number and the sequence of arms entered were also recorded. The parameters were activity, defined as the number of arms entered, and percent alternation, calculated as the number of alternations or triads.

\section{Moriz Water Maze}

A wide plastic cylindrical tank of about $120 \mathrm{~cm}$ width, that is surrounded by a wall $(45 \mathrm{~cm})$ and filled with water that was made opaque to reduce light penetration $\left(25^{\circ} \mathrm{C}\right)$ was set up for 


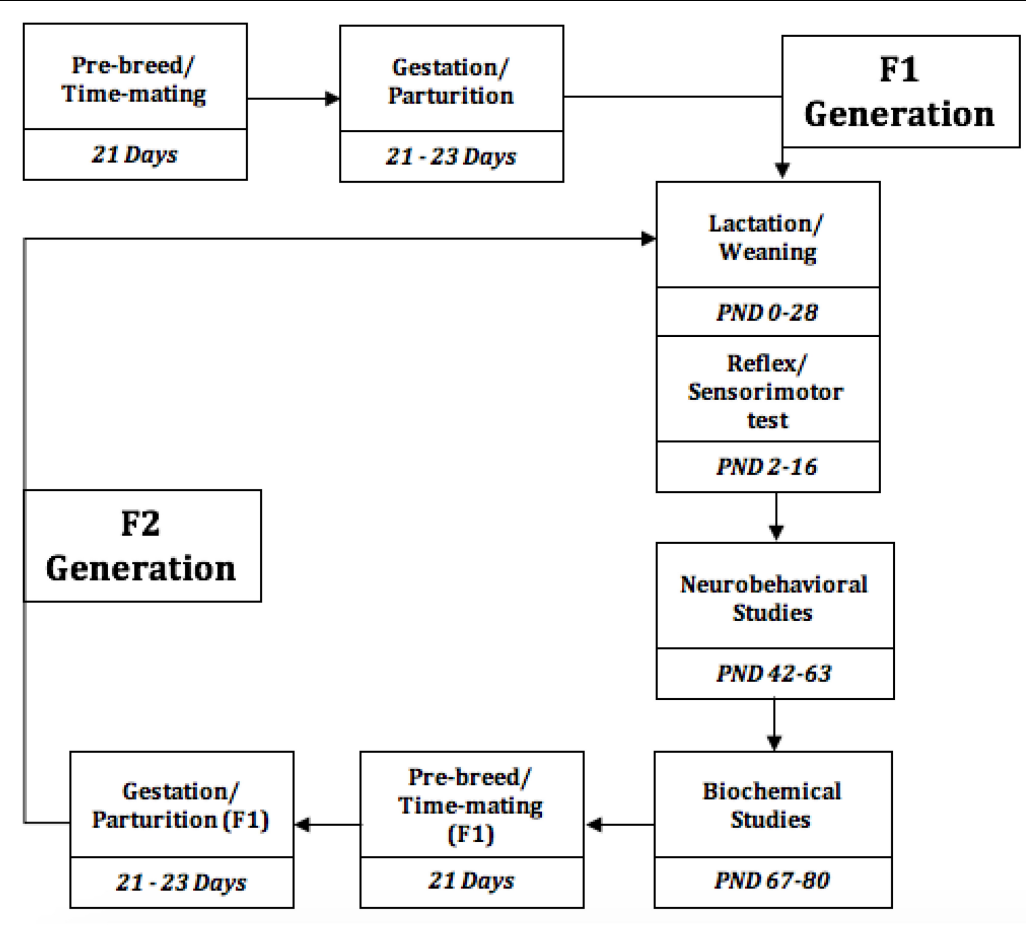

FIGURE 1 | Experimental Timeline of the events, from the study initiation to termination. PND, Postnatal days.

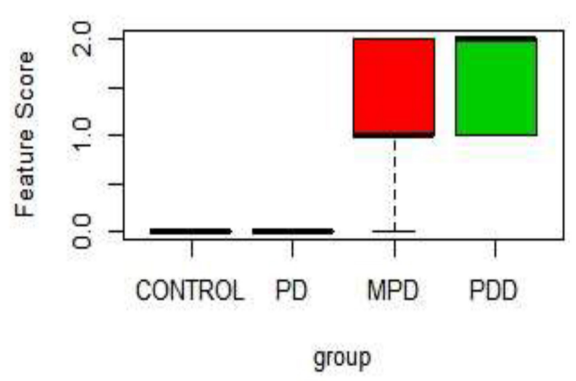

FIGURE 2 | Boxplot of Physical characteristic scores in the different diet group. PDD: 5\% Protein Diet, Mild PD: 10\% Protein Diet, PD: 21\% Protein Diet, and CONTROL. Score Keys - Scale: 0-2: 0, No characteristic display; 1 , Mild characteristics display; 2, Prominent Characteristics display. Features Scored: Paleness, Muscle wasting, Stunted growth, Alopecia, Edema, and lesion.

the experiment. A rescue platform, $10 \mathrm{~cm}$ high was hidden at the center of the tank, below water level. Rats were given three swimming sessions on each of five consecutive days. At trial, the time taken to locate the platform (escape latency) was measured (Wang et al., 2017).

\section{Serotonin and Dopamine Quantification}

The brain serotonin and dopamine concentration in the rat were determined using high performance liquid chromatography (HPLC), Agilent 100 series with VWD detector degasser, Quat Pump, Col Com and a manual injector system. Striatum tissues in the brain were collected, homogenized, deproteinized by chilled acetonitrile and filtered using syringe filter in preparation for injection. Serotonin and dopamine contents were determined by comparing the peak height ratios of the standards (5-HT and dopamine) used as calibrators and the chromatogram of unknown (Ebuehi and Abey, 2016).

\section{Brain Antioxidant Assays}

The brain antioxidant capacity was measured using the following biomarkers.

\section{Determination of Reduced Glutathione (GSH)}

The reduced glutathione level was determined based on the yellow color formed after reacting with 5,5'dithiobis- 2nitrobenzoic acid (DTNB), which is then read at $412 \mathrm{~nm}$ (Ellman, 1978).

\section{Determination of Catalase Activity (CAT)}

The activity of the enzyme catalase was analyzed by measuring the initial rate of hydrogen peroxide $(50 \mathrm{mM})$ decomposition, where one unit is the amount of enzyme that hydrolyses 1 mol. of $\mathrm{H}_{2} \mathrm{O}_{2}$ per minute, following method described by Cohen et al. (1996).

\section{Determination of Super Oxide Dismutase Activity}

The super oxide dismutase (SOD) activity was determined according to the modified method of Sun and Zigman (1978), determined by the ability of SOD to inhibit the autoxidation of epinephrine, taken as the difference between superoxide anion production and decomposition, measured by the increase in absorbance at $320 \mathrm{~nm}$. 
$\mathbf{F}_{1}$

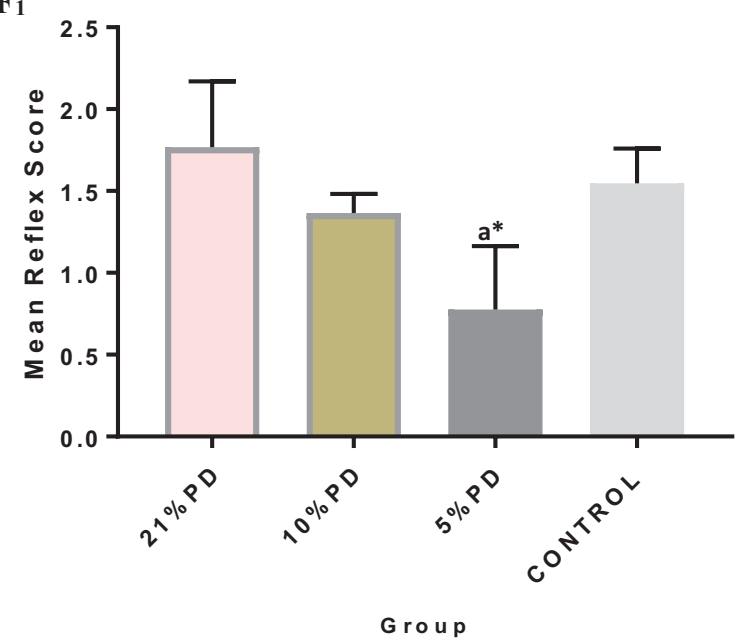

$\mathbf{F}_{2}$

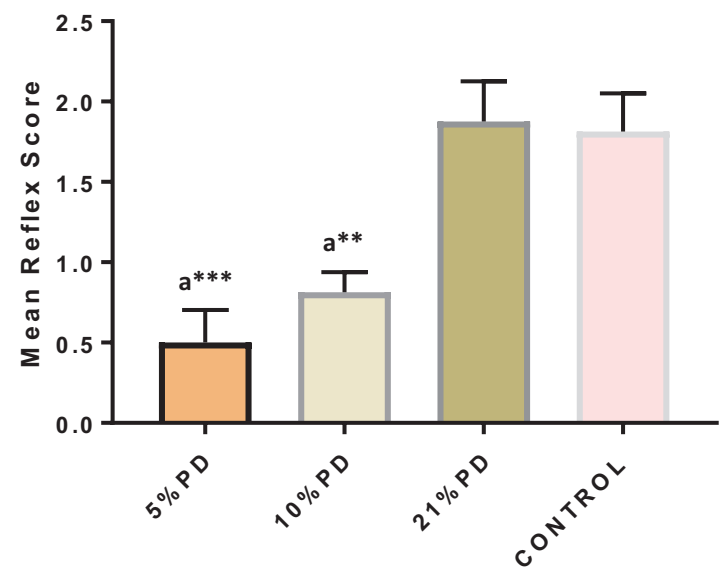

Group

FIGURE 3 | Mean reflex response score in each of the diet groups of rats of $F_{1}$ and $F_{2}$-generations. Data are expressed as mean \pm SEM, Control (standard rat chow containing 16-18\% Protein), 21\% PD (Upgraded daily recommended intake), 5\% (Protein deficient diet), and 10\% (Mild protein deficient diet). ${ }^{a}$ significantly different from $21 \%$ diet group and or control. ${ }^{*} P<0.05,{ }^{*} P<0.001,{ }^{* * *} P<0.0001$.
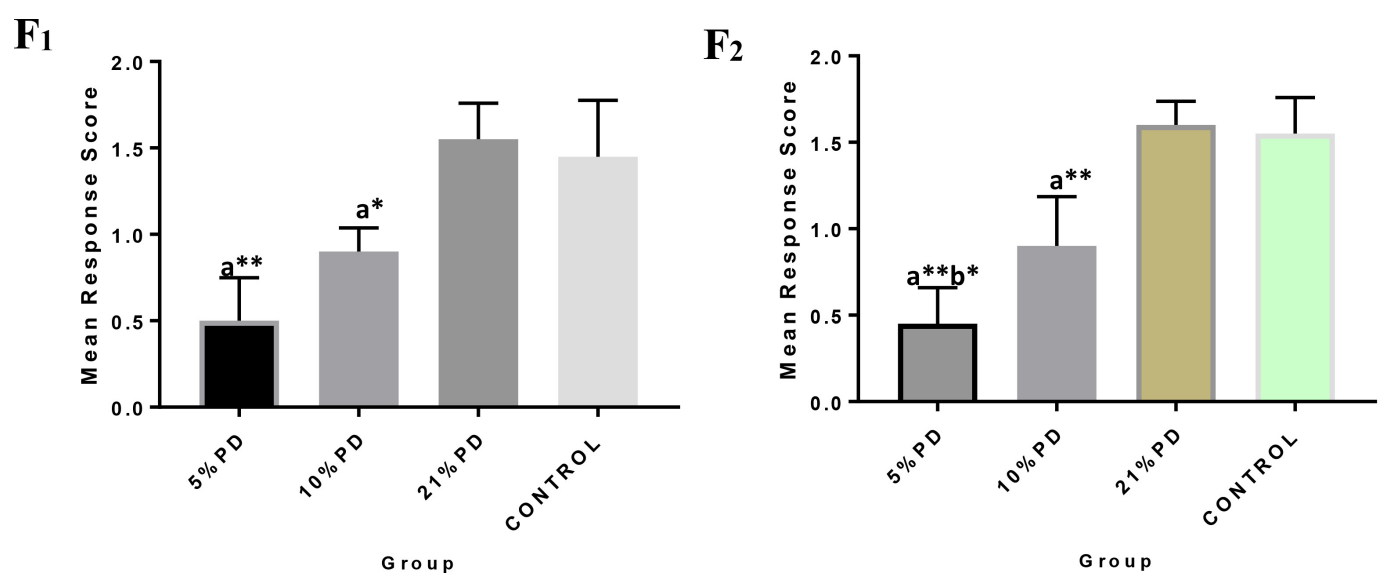

FIGURE $4 \mid F_{1}$ and $F_{2}$ Mean response score of the postural reaction in each of the diet group of rats. Data are expressed as mean $\pm \mathrm{SEM}$, Control (standard rat chow containing 16-18\% Protein), 21\% PD (upgraded daily recommended intake), 5\% (Protein deficient diet), and 10\% (Mild protein deficient diet). ${ }^{a}$ significantly different from $21 \%$ diet group and or control. ${ }^{b}$ significantly different from the $10 \%$ diet group. ${ }^{*} P<0.05,{ }^{* *} P<0.001$.

\section{Determination of Lipid Peroxidation Malondialdehyde (MDA)}

Malondialdehyde is red specie absorbing at $535 \mathrm{~nm}$ (Buege and Aust, 1978). It is formed from the breakdown of polyunsaturated fatty acids, serving as a convenient index for determining the extent of lipid peroxidation that reacts with thiobarbituric acid. Absorbance taken at $535 \mathrm{~nm}$, corresponds to the concentration of MDA per mg protein.

\section{Determination of Concentration of Nitric Oxide}

Nitric Oxide was assayed by the Griess reaction method (Bryan and Grisham, 2007). $0.2 \mathrm{ml}$ of the Griess reagent mixed with $3 \mathrm{ml}$ of the sample and incubated at room temperature for $10 \mathrm{~min}$. Absorbance was read using the spectrophotometer at $540 \mathrm{~nm}$.
This procedure is not stoichiometric and thus, a standard curve of sodium nitrite was plotted in order to extrapolate the values for unknown samples.

\section{Statistical Analysis}

All data were analyzed with maternal and weaning diets as factors. Results are presented as the mean \pm SEM. Statistical analysis was performed using GraphPad Prism 7.0 for analysis of variance (ANOVA) followed by post hoc Turkey's test, when appropriate; $P \leq 0.05$ is considered significant.

\section{RESULTS}

Table 1 shows the score on a scale of $0-2$ based on prominence/severity of characteristic displayed. Control and 
$\mathbf{F}_{1}$

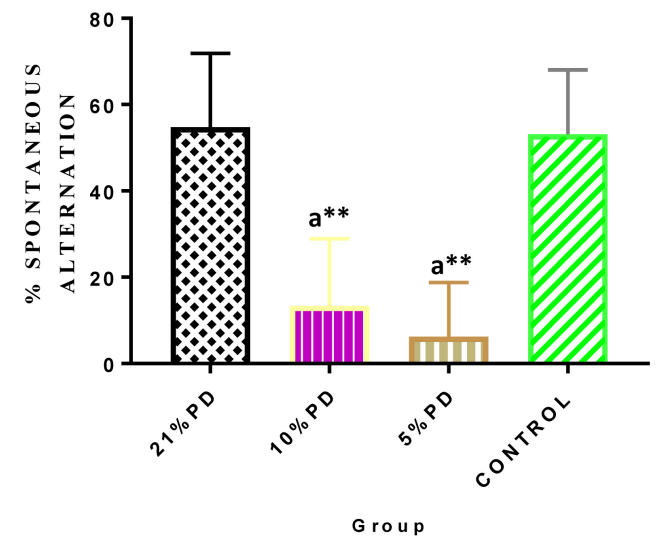

$\mathbf{F}_{2}$

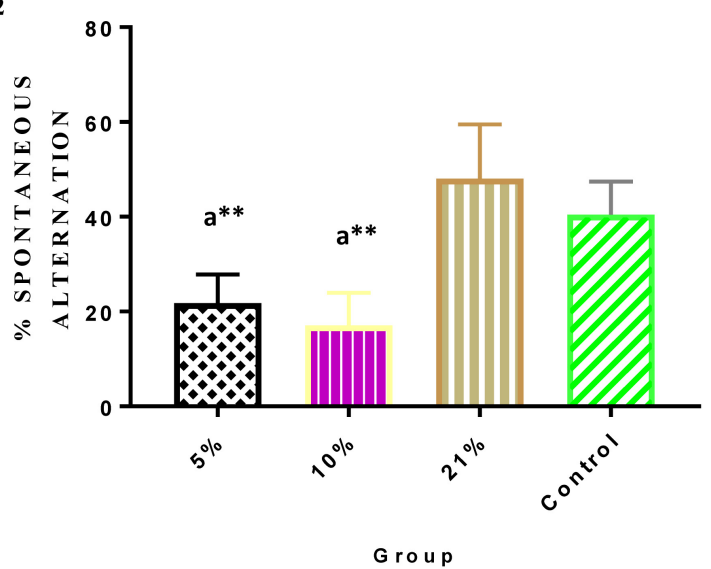

FIGURE 5 | Y-maze Percentage Spontaneous Alternation in each of the diet group of $F_{1}$ and $F_{2}$-generation rats. Data are expressed as mean \pm SEM. Statistically significant difference between individual group and the hypothetical value of $50 \%$ at $P<0.05$. Spontaneous alteration $\%=\frac{\# \text { spontanuos alternation }}{\text { total number of arm entries }-2} \times 100$ Control (standard rat chow containing 16-18\% Protein), 21\% PD (Upgraded daily recommended intake), $5 \%$ (Protein deficient diet), and 10\% (Mild protein deficient diet). ${ }^{a}$ significantly different from $21 \%$ diet group and or control. **P $<0.001$.

\section{$\mathbf{F}_{1}$}

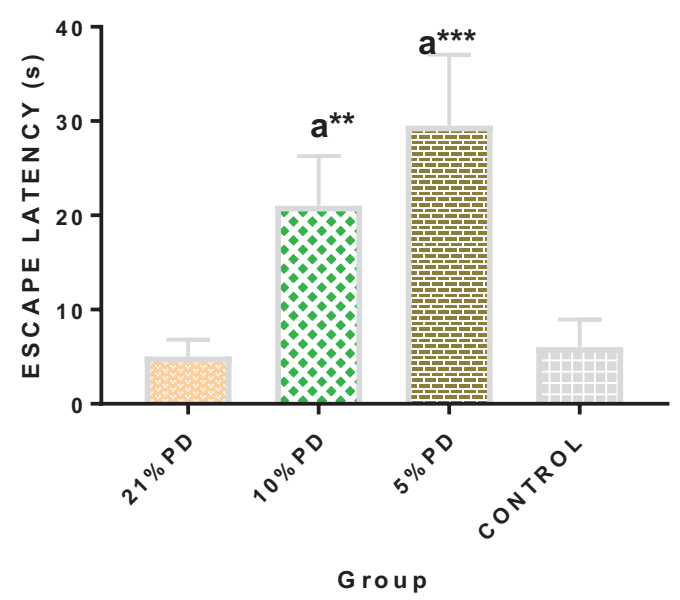

$\mathbf{F}_{2}$

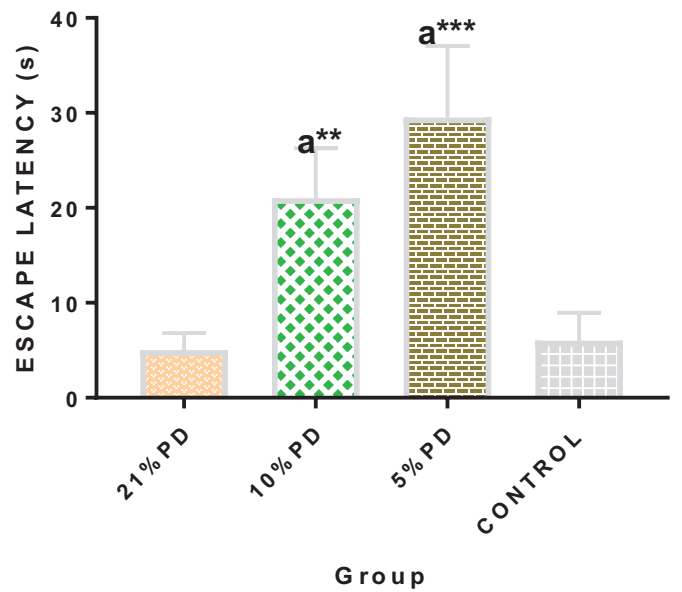

FIGURE 6 | Mean Moriz Water Maze Experiment showing the Escape Latency demonstrated by each group in $\mathrm{F}_{2}$-generations. Data are expressed as mean \pm SEM, Control (standard rat chow containing 16-18\% Protein), 21\% PD (upgraded daily recommended intake), 5\% (Protein deficient diet), and 10\% (Mild protein deficient diet). ${ }^{a}$ significantly different from $21 \%$ diet group and or control. ${ }^{* *} P<0.001,{ }^{* * *} P<0.0001$.

$21 \% \mathrm{PD}$ had no display of the scored features, this relationship is represented on the box-plot (Figure 2).

In Figure 2, the 5\% PD and 10\% PD had characteristic score skewed toward the positive, reflecting a higher display, while control and 21\% PD skewed toward the negative, with no visible display. These distinctive features of perinatal protein deficiency compared to control and $21 \%$ protein diet group include; prominent paleness, muscle wasting, hair loss and stunted growth.

Significantly higher response time in the protein deficient models (Figure 3) as well as a negative postural score (Figure 4) in the negative geotaxis test at the early postnatal days of the protein deficient diet groups. In Figure 5, Y-maze\% spontaneous alternation result shows significant deficit in the $5 \%$ protein diet group in the two $(2)$ generations $\left(\mathrm{F}_{1}\right.$ and $\left.\mathrm{F}_{2}\right)$ while $10 \%$ was only significant in $\mathrm{F}_{1}$-generation. In addition, escape latency observed in Figure 6 shows that the malnourished groups spent longer time to locate the rescue platform during trial sessions, a display of cognitive deficit. With significant dietary factor influence, at $P<0.001$.

Serotoninergic and dopaminergic neurotransmission, important in neurobehavioral control and cognition was 


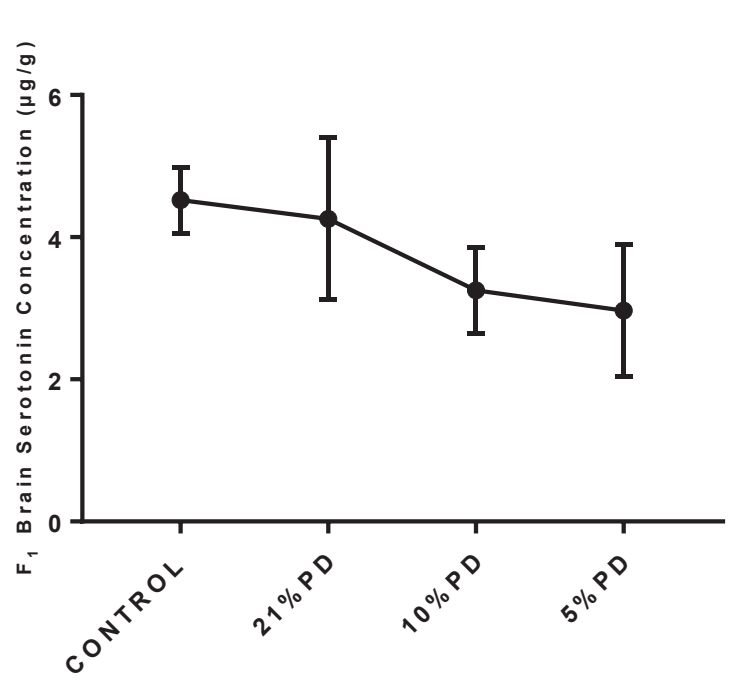

Group

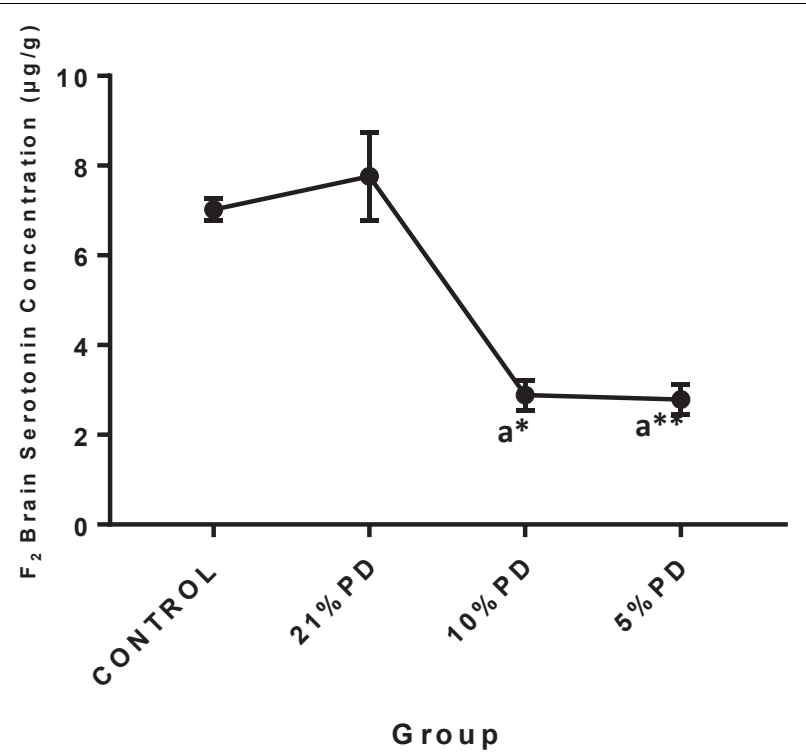

FIGURE 7 | Concentration of Brain Serotonin $(\mu \mathrm{g} / \mathrm{g})$ in the $F_{1}$ and $F_{2}$-generations of rat in each of the different diet groups. Data are expressed as mean \pm SEM, Control (standard rat chow containing 16-18\% Protein), 21\% PD (upgraded daily recommended intake), 5\% (Protein deficient diet), 10\% (Mild protein deficient diet). a significantly different from $21 \%$ diet group and or control. ${ }^{*} P<0.05,{ }^{* *} P<0.001$

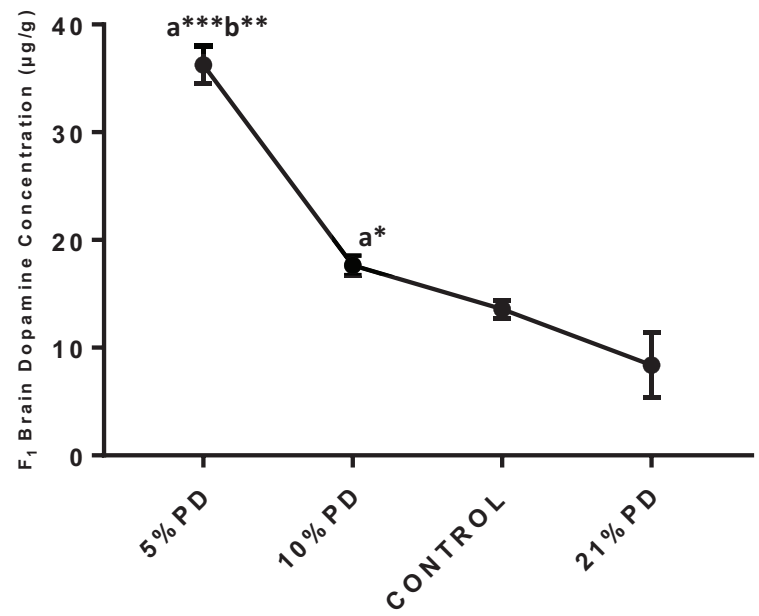

Group

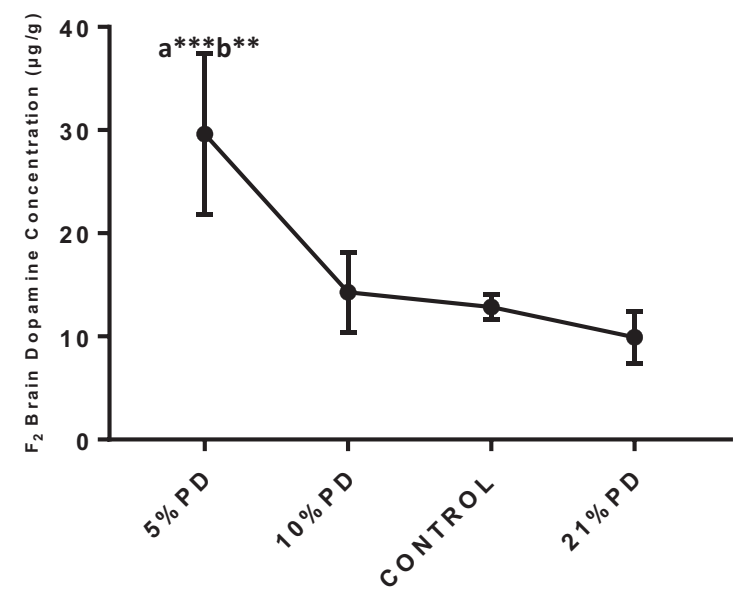

Group

FIGURE 8 | Concentrations of Brain Dopamine $(\mu \mathrm{g} / \mathrm{g})$ in the $F_{1}$ and $F_{2}$-generations in each of the different diet group of rats. Data are expressed as mean \pm SEM, Control (standard rat chow containing 16-18\% Protein), 21\% PD (upgraded daily recommended intake), 5\% (Protein deficient diet), 10\% (Mild protein deficient diet). ${ }^{a}$ significantly different from $21 \%$ diet group and or control. ${ }^{b}$ significantly different from the $10 \%$ diet group. ${ }^{*} P<0.05,{ }^{* *} P<0.001,{ }^{* * *} P<0.0001$.

perturbed in the nutritionally stressed models (Figures 7,8 ) which persists to subsequent generation. Endogenous antioxidant status of the malnourished groups were suppressed. Tables 2 and 3, with significant increase in the Malondialdehyde level.

\section{DISCUSSION}

Neurodevelopment is peculiar to early life and this stage is critically dependent on maternal protein intake. Dietary protein deficiency and its corresponding effect on neurodevelopment critical to survival and quality of life that subsequently follows, perturbs the neurotransmission system and cognition programing. The brain in an attempt to compensate for the nutritional inadequacies, may change its functional activation, as an important signature for the reorganization, providing explanation for the various chemical alterations and behavioral display reported in the result.

As earlier stated by Guo and Katta (2017), protein is crucial to the health of hair follicles, and hence the alopecia observed in 
TABLE 1 | Physical features of rats fed different protein diets in the $F_{1}$-generation.

\begin{tabular}{lcccc}
\hline Characteristics & Control & $\mathbf{2 1 \%}$ PD & $\mathbf{1 0} \%$ PD & $\mathbf{5 \%}$ PD \\
\hline Paleness & 0 & 0 & 0 & 2 \\
Muscle wasting & 0 & 0 & 1 & 2 \\
Stunted growth & 0 & 0 & 1 & 2 \\
Alopecia (hair thinning and loss) & 0 & 0 & 1 & 2 \\
Edema & 0 & 0 & 2 & 1 \\
Lesion & 0 & 0 & 2 & 1 \\
\hline
\end{tabular}

Features Scored: Paleness, Muscle wasting, Stunted growth, Alopecia, Edema, and lesion. Score Keys - Scale: 0-2: 0, No characteristic display; 1, Mild characteristics display; 2, Prominent Characteristics display.

the protein deficient groups, also in accordance with the previous research (Belluscio et al., 2014), stunted growth is attributed to the suboptimal intrauterine condition of the nutritionally challenged group.

Protein deficiency caused perturbations in brain development observed as delayed neurological reflex and postural response. Therefore, the neuronal response of these deficient models has been negatively impacted leading to the weakening of the nerves and deterring communications and potentiation essential for learning (Naik et al., 2015). The working memory and cognition of the protein deficient group lagged significantly; taking more time to perform learned task, this suggests a fundamental defect in the neurodevelopmental process and degeneration in brain function, which persists in both parent and progeny.

Malnutrition in early life as earlier reported (Chertoff, 2015), affects the neurochemistry and morphology of the hippocampal structure, which is known to be involved in learning and memory. One of the key factors on which brain function depends is the availability of neurotransmitter molecule for release into synapse, this alteration in the neurotransmitter scale may therefore underlie the functional deficit displayed by the protein malnourished groups. In addition, dopamine alteration perturbs neural encoding, this suggests a clinical association with other dysfunctions such as anxiety and psychosis (Ebuehi et al., 2001, 2009; Kelly et al., 2017). In malnutrition condition, free radicals mediate tissue damage, due to the inadequate protective and repair mechanisms in the protein-deficient models (Feoli et al., 2006). Therefore, maternal undernutrition may contribute to the transgenerational imbalance in the brain redox status of the following generation. The developmental behavior, and cognitive deficits observed on perinatal malnourished models might derive their effects from mechanisms which include the perturbed redox status and neurotransmission as an insult to the Brain.

\section{CONCLUSION}

Perinatal protein deficiency altered the brain development in parent and offspring. Increased oxidative damage and altered neurotransmission in the brain of $\mathrm{F}_{1}$ generation of rats, underlie the perturbed neurobehavioral display and cognitive deficit in the nutritionally challenged groups. Therefore, persistent perinatal exposure to protein malnutrition increases the risk of cognitive defect and other brain disorders in subsequent generations. This study affirms the importance of dietary protein at the early developmental life process laying emphasis on the mechanism associated with the resultant transgenerational neurodevelopment and cognitive impairment following persistent perinatal protein deficiency. More work

TABLE 2 | Oxidative stress biomarkers in different diet groups of $F_{1}$-generation of rat models.

\begin{tabular}{|c|c|c|c|c|c|c|}
\hline Group & Total protein $(\mathrm{mg} / \mathrm{ml})$ & Catalase (U/L/min) & GSH ( $\mu \mathrm{mol} / \mathrm{L})$ & SOD (U/L/min) & MDA ( $\mu \mathrm{mol} / \mathrm{L})$ & Nitric oxide (mg/ml) \\
\hline Control & $31.43 \pm 6.10$ & $20.72 \pm 4.00$ & $45 \pm 3.80$ & $0.0249 \pm 0.01$ & $0.29 \pm 0.09$ & $6.989 \pm 1.20$ \\
\hline $21 \%$ PD & $41.35 \pm 8.00$ & $15.92 \pm 3.99$ & $53.14 \pm 4.00$ & $0.0438 \pm 0.01$ & $1.02 \pm 0.9$ & $7.147 \pm 0.40$ \\
\hline $10 \%$ PD & $34.16 \pm 1.41$ & $21.29 \pm 1.96$ & $45.89 \pm 0.98$ & $0.1989 \pm 0.03$ & $2.5 \pm 0.7^{a * *}$ & $1.585 \pm 0.70^{\mathrm{a} * * \mathrm{~b} * *}$ \\
\hline $5 \%$ PD & $20.23 \pm 2.98^{\mathrm{a} *}$ & $34.89 \pm 5.00^{\mathrm{a} * * \mathrm{~b} * \mathrm{c} *}$ & $37.74 \pm 4.70^{a *}$ & $0.00334^{a * *} \pm 0.0$ & $24.55 \pm 4.6^{\mathrm{a} * * \mathrm{~b} * *}$ & $1.6 \pm 1.10^{\mathrm{a} * \mathrm{~b} * *}$ \\
\hline
\end{tabular}

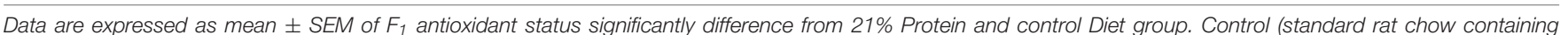

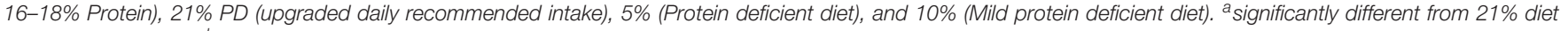
group and or control. ${ }^{b}$ significantly different from the $10 \%$ diet group. ${ }^{*} P<0.05,{ }^{* *} P<0.001$.

TABLE 3 | Oxidative stress biomarkers in different diet groups of $F_{2}$-generation of rat models.

\begin{tabular}{|c|c|c|c|c|c|c|}
\hline Group & $\begin{array}{l}\text { Total protein } \\
\text { (mg/ml) }\end{array}$ & $\begin{array}{l}\text { Catalase } \\
\text { (U/L/min) }\end{array}$ & $\begin{array}{c}\text { GSH } \\
(\mu \mathrm{mol} / \mathrm{L})\end{array}$ & $\begin{array}{c}\text { SOD } \\
\text { (U/L/min) }\end{array}$ & $\begin{array}{c}\text { MDA } \\
(\mu \mathrm{mol} / \mathrm{L})\end{array}$ & $\begin{array}{l}\text { Nitric oxide } \\
(\mathrm{mg} / \mathrm{ml})\end{array}$ \\
\hline Control & $1.9166 \pm 0.19$ & $5.9259 \pm 0.40$ & $13.051 \pm 1.5$ & $0.0116 \pm 0.002$ & $0.0673 \pm 0.01$ & $9.40 \pm 0.94$ \\
\hline $21 \%$ PD & $1.965 \pm 0.27$ & $8.3951 \pm 0.56$ & $16.219 \pm 1.3$ & $0.0261 \pm 0.001$ & $0.0289 \pm 0.01$ & $11.82 \pm 0.09$ \\
\hline $10 \% \mathrm{PD}$ & $1.0224 \pm 0.07^{\mathrm{a} * \mathrm{~b} *}$ & $60.25 \pm 6.90^{\mathrm{a} * * \mathrm{~b} * *}$ & $11.46024 \pm 1.1$ & $0.050435^{\mathrm{b} *} \pm 0.001$ & $0.279 \pm 0.1^{\mathrm{a} * * \mathrm{~b} * *}$ & $8.08 \pm 1.34$ \\
\hline $5 \%$ PD & $0.878 \pm 0.01^{\mathrm{a} * \mathrm{~b} *}$ & $75.062 a^{* * b * *}$ & $9.065 \pm 0.7^{a *}$ & $0.0809 \pm 0.0001^{\mathrm{a} * * \mathrm{~b} * * \mathrm{c} *}$ & $0.356 \pm 0.04^{\mathrm{a} * * \mathrm{~b} * *}$ & $3.264 \pm 1.0^{\mathrm{a} * \mathrm{~b} * \mathrm{C} *}$ \\
\hline
\end{tabular}

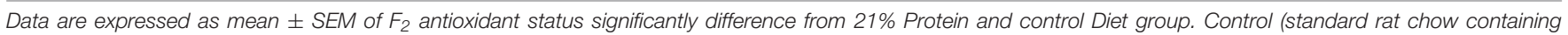

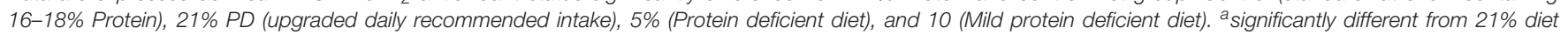
group and or control. ${ }^{b}$ significantly different from the $10 \%$ diet group. ${ }^{*} P<0.05,{ }^{* *} P<0.001$. 
needs to be done to establish a molecular mechanism for these effects which could be linked to neurodegenerative disorders.

\section{DATA AVAILABILITY}

The datasets generated for this study are available on request to the corresponding author.

\section{REFERENCES}

Belluscio, L. M., Berardino, B. G., Ferroni, N. M., Ceruti, J. M., and Cánepa, E. T. (2014). Early protein malnutrition negatively impacts physical growth and neurological reflexes and evokes anxiety and depressive-like behaviors. Physiol. Behav. 129, 237-254. doi: 10.1016/j.physbeh.2014.02.051

Black, M. M. (2018). Impact of nutrition on growth, brain, and cognition. Nestle Nutr. Inst. Workshop Ser. 89, 185-195. doi: 10.1159/000486502

Bryan, N. S., and Grisham, M. B. (2007). Methods to detect nitric oxide and its metabolites in biological samples. Free Radic. Biol. Med. 43, 645-657. doi: 10.1016/j.freeradbiomed.2007.04.026

Buege, J., and Aust, S. (1978). "Microsomal lipid peroxidation," in Methods in Enzymol, eds S. Fleisher and L. Packer (New York, NY: Academic Press Inc), 302-310.

Chan, R. C. K., Xu, T., Li, H.-J., Zhao, Q., Liu, H.-H., Wang, Y., et al. (2011). Neurological abnormalities and neurocognitive functions in healthy elder people: a structural equation modeling analysis. Behav. Brain Funct. 7:32. doi: 10.1186/1744-9081-7-32

Chertoff, M. (2015). Protein malnutrition and brain development. Brain Disord. Ther. 4:3. doi: 10.4172/2168-975X.1000171

Cohen, G., Kim, M., and Ogwu, V. (1996). A modified catalase assay suitable for a plate reader and for the analysis of brain cell cultures. J. Neurosci. Methods 67, 53-56. doi: 10.1016/0165-0270(96)00011-8

Colombo, J., Koletzko, B., and Lampl, M. (2018). "Recent research in nutrition and growth," Nestlé Nutr Inst Workshop Ser. Nestlé Nutrition Institute, Vol. 89, Switzerland/S: Karger AG., Basel, 175-184. doi: 10.1159/0004 86501

Ebuehi, O. A. T., and Abey, N. O. (2016). Impact of Marijuana (Cannabis sativa) on some neurochemicals and cognitive function of sprague-dawley rats. Res. Neurosci. 5, 1-9. doi: 10.5923/j.neuroscience.20160501.01

Ebuehi, O. A. T., Bishop, S. A., Famuyiwa, O. O., Akinwande, A. I., and Ladenegan, O. A. (2001). Biogenic amine metabolism and blood chemistry of psychiatric patients. Afr. J. Med. Med. Sci. 30, 269-273.

Ebuehi, O. A. T., Ikanone, C. E., Balogun, A. A., Akinwande, A. I, and Famuyiwa, O. O. (2009). Effects of administration of sertraline, clozapine, amitriptyline and imipramine on the brain serotonin, liver enzymes and blood chemistry of rabbits. Intern. J. Biol. Chem. Sci. 3, 85-94.

Ellman, G. (1978). Tissue sulfuhydryl groups. Arch. Biochem. Biophys. 82, 70-77. doi: 10.1016/0003-9861(59)90090-6

Feoli, A. M., Siqueira, I. R., Almeida, L., Tramontina, A. C., Vanzella, C., Sbaraini, S., et al. (2006). Effects of protein malnutrition on oxidative status in rat brain. Nutrition 22, 160-165. doi: 10.1016/j.nut.2005.06.007

\section{AUTHOR CONTRIBUTIONS}

$\mathrm{NA}$, OE, and NI designed the study. OE and NI constructively supervised the analyses of the study. NA managed the analyses, statistical analysis, the literature search, and wrote the first draft of the manuscript. All authors read and approved the final manuscript.

Guo, E. L., and Katta, R. (2017). Diet and hair loss: effects of nutrient deficiency and supplement use. Dermatol. Pract. Concept. 7, 1-10. doi: 10.5826/dpc.0701a01

Kelly, M. D., Ziauddeen, H., Vestergaard, M. D., Spencer, T., Schultz, W., and Fletcher, P. C. (2017). Dopamine modulates adaptive prediction error coding in the human midbrain and striatum. J. Neurosci. 37, 1708-1720. doi: 10.1523/ JNEUROSCI.1979-16.2016

Hurley, K. M., Yousafzai, A. K., and Lopez-Boo, F. (2016). Early child development and nutrition: a review of the benefits and challenges of implementing integrated interventions. Adv. Nutr. 7, 357-363. doi: 10.3945/an.115.010363

Naik, A. A., Patro, I. K., and Patro, N. (2015). Slow physical growth, delayed reflex ontogeny, and permanent behavioral as well as cognitive impairments in rats following intra-generational protein malnutrition. Front. Neurosci. 9:446. doi: 10.3389/fnins.2015.00446

Sosa-Larios, T. C., Miliar-Garcia, A. A., Reyes-Castro, L. A., Morimoto, S., and Jaramillo-Flores, M. E. (2017). Alterations in lipid metabolism due to a proteinrestricted diet in rats during gestation and/or lactation. Food Funct. doi: 10. 1039/c7fo90045g [Epub ahead of print].

Sun, M., and Zigman, S. (1978). An improved spectrophotometric assay for superoxide dismutase based on epinephrine autoxidation. Anal. Biochem. 90, 81-89. doi: 10.1016/0003-2697(78)90010-6

Wang, M., Uchiumi, O., Ogiso, H., Shui, Y., Zou, J., Hashizume, C., et al. (2017). Stressful learning paradigm precludes manifestation of cognitive ability in sphingomyelin synthase-2 knockout mice. Behav. Brain Res. 319, 25-30. doi: 10.1016/j.bbr.2016.11.010

Wu, G. (2016). Dietary protein intake and human health. Food Funct. 7, 1251-1265. doi: $10.1039 / \mathrm{c} 5$ fo01530h

Yarube, I. U., Ayo Magaji, R. A., Umar, J. A., Yusuf, N. W., Alhassan, A. W., and Saleh, M. I. A. (2016). Outcome of sub-acute insulin administration on long-term visuospatial and short-term working memory in mice. J. Afr. Assoc. Physiol. Sci. 4, 41-47.

Conflict of Interest Statement: The authors declare that the research was conducted in the absence of any commercial or financial relationships that could be construed as a potential conflict of interest.

Copyright (c) 2019 Abey, Ebuehi and Imaga. This is an open-access article distributed under the terms of the Creative Commons Attribution License (CC BY). The use, distribution or reproduction in other forums is permitted, provided the original author(s) and the copyright owner(s) are credited and that the original publication in this journal is cited, in accordance with accepted academic practice. No use, distribution or reproduction is permitted which does not comply with these terms. 